\title{
Porous underwater chamber (PUC) for in-situ determination of nutrient and pollutant bioavailability to microorganisms
}

\author{
Christel S. Hassler ${ }^{*}$, Michael R. Twiss², Dana F. Simon³, and Kevin J. Wilkinson ${ }^{3}$ \\ ${ }^{1}$ CSIRO Atmospheric and Marine Research, Castray Esplanade-Unit 4, GPO Box 1538, Hobart TAS 7001, Australia \\ ${ }^{2}$ Department of Biology/Center for the Environment, Clarkson University, Potsdam, NY, 13699, USA \\ ${ }^{3}$ Department of Chemistry, University of Montreal, P.O. Box 6128, Montreal, QC, H3C 3J7, Canada
}

\begin{abstract}
Physical (e.g., temperature and light) and biogeochemical (e.g., cycling) parameters are known to affect bioavailability and toxicity of nutrients and pollutants to microorganisms. A system that would allow exposure of selected microorganisms to in situ conditions could provide relevant and novel evaluations of bioavailability. A simple and low cost $37 \mathrm{~mL}$ porous underwater chamber (PUC), in which test microorganisms are exposed to field conditions, is presented. The PUC is a thin, acrylic cylinder with polycarbonate membranes on each side, providing an optimal $\left(75 \mathrm{~cm}^{2}\right)$ exchange with the external solution. Regardless of the membrane pore size $(0.4$ and $5 \mu \mathrm{m})$, the PUC required $10 \mathrm{~h}$ to equilibrate with the external solution, close to the theoretical time determined for the diffusion of a model compound, the Suwannee River fulvic acid. For in situ use, the PUCs can be filled with filtered water to minimize the equilibration time. The system was validated in 20 to $60 \mathrm{~L}$ artificial freshwater by evaluating (1) Cd bioaccumulation by the microalga Chlamydomonas reinhardtii and (2) iron bioavailability to a cyanobacterial bioreporter in comparison with conventional bottle assays. The use of the PUC resulted in no significant differences in Cd uptake fluxes or iron bioavailability. Field experiments undertaken on Lake Erie demonstrated that the PUCs could be used to evaluate the contribution of particulate iron to iron bioavailability. Because the PUCs might not correctly reflect bioavailability for substances at low concentrations with high biouptake fluxes, a critical discussion with respect on the rate-limiting steps of the device is presented. Several considerations that might facilitate the appropriate use of the PUCs are given.
\end{abstract}

Microorganisms, especially plankton (Dokulil 2003), are commonly used to evaluate the toxicological or nutritive status of natural waters (Streb et al. 2002; Janssen and Heijerick 2003; Lin et al. 2005). For this purpose, it is possible to use either indigenous organisms (e.g., Intwala et al. 2008) or pure cultures

*Corresponding author: Phone: +61 (3) 6232 5026; Fax: + 61 (3) 6232 5000; E-mail: Christel.Hassler@csiro.au

\section{Acknowledgments}

We thank Sonya Havens and Michel Martin for technical assistance, Steve Wilhelm for the opportunity to join the C.C.G.S. Limnos on Lake Erie and Jacques Buffle, Edward Butler, Richard Matear and two anonymous reviewers for comments on previous versions of the manuscript, and Madeline Twiss for the hands in Fig. 1. We also wish to acknowledge Richard Matear's input to model diffusion inside the PUCs. This study was supported by a collaborative grant from the National Science Foundation (Chem Oce No. 0327730) to MRT, RML McKay, and GS Bullerjahn and by Clarkson University. CSH and DFS received funding from the Swiss National Science Foundation (No. PBGEA-104637) and the European Commission's sixth framework program (ECODIS project, subpriority 6.3

"Global Change and Ecosystems," contract 518043). This is Clarkson Center for the Environment Contribution No. 333. of organisms taken from culture collections (e.g., Janssen and Heijerick 2003). While organisms that are isolated from a given water of interest are likely to be more representative, it is often difficult to define a control condition that represents the "no effect" situation since the natural communities are already adapted to the existing conditions. Furthermore, when natural waters are transferred from the field to the lab, the conditions under which the assays are performed will invariably fail to reflect the biophysicochemistry under which the sample was collected, e.g., different light, temperature, pressure, colloid and particle content (following sedimentation or filtration). Since natural systems are always dynamic, the removal of particles will perturb the biogeochemical cycling of nutrients and pollutants by reducing sedimentation fluxes or by removing grazing organisms (Twiss et al. 1996). Temperature affects both chemical (e.g., rate constants) and biological processes (e.g., metabolism, membrane permeability), simultaneously. Such changes will affect both the speciation and bioavailability of trace pollutants or nutrients (Sunda and Huntsman 2003; Wilkinson and Buffle 2004; Hassler et al. 2006). 
For macroscopic organisms, it is often possible to get around some of the inconveniences of laboratory experiments by performing transplant experiments (Forrester 2005) where organisms are moved from a contaminated media to a pristine one (and vice versa). Although this experimental protocol is commonly not employed for microorganisms, it may provide an interesting area for future research. Subcellular biological responses (e.g., phytochelatin content or enzymatic activity, Ahner et al. 1998; Dokulil 2003), and the development of biosensors are especially relevant given the recent determination of the (complete) genomes of a number of environmentally relevant microorganisms (e.g., Armbrust et al. 2004; Binnewies et al. 2006). Although analytical techniques are currently available to perform pollutant or nutrient bioavailability assays under controlled laboratory conditions, there are currently no simple, nonperturbing tools that allow the simple, in situ exposure of standard microorganisms.

Plankton ecologists have examined the use of semi-permeable devices, mainly dialysis sacs, for in situ exposures of test organisms. Devices have been used to assess nutrient requirements (Durrieu et al. 2003) or pressure due to growth and grazing (Furnas 1982, Furnas 1991). Semi-permeable membranes have frequently been used to separate phytoplankton from the influence of chemical constituents of high molecular mass, including humic substances $(>1 \mathrm{kDa})$, in order to determine their influence on the binding and bioavailability of toxic compounds (Twiss et al. 1999). Teflon membranes (Tan 1986), regenerated cellulose dialysis membranes (Furnas 1982, Twiss et al. 1999), and polycarbonate membranes (Furnas 1982, 1991) have been used in the past. Furnas (1982) showed that diffusion of solutes through polycarbonate membranes was more rapid than through regenerated cellulose membranes, resulting in higher growth rates.

In the present study, we have developed a user-friendly, Porous Underwater Chamber (PUC) that is capable of assessing trace metal bioavailability. The simple, low-cost device is designed to facilitate the exposure of controlled laboratory cultures to natural waters. Its exposure chamber is in contact with the external media via two large polycarbonate membranes.

To verify several potential limitations of this device, equilibration times were measured for various solutes and membrane pore sizes. Use of this device was tested by comparing the response obtained for several phytoplanktonic microorganisms with conventional bottle assays, both under laboratory and field conditions. In the laboratory experiments, characterized situations were studied, namely cadmium bioaccumulation for a green alga (Kola and Wilkinson 2005) and iron bioavailability for a cyanobacterial bioreporter (Hassler and Twiss 2006; Hassler et al. 2006). Use of the PUC was field tested by using it to assess iron bioavailability in filtered and whole Lake Erie water in on board incubators. The proposed procedure provides a promising means to expose reference microorganisms to in situ conditions, thereby minimizing the

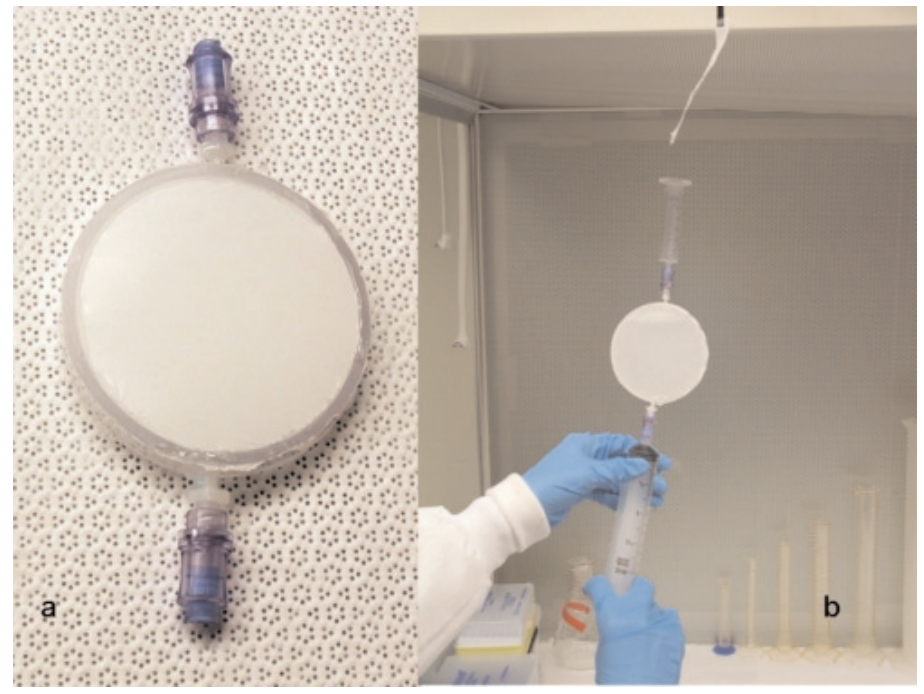

Fig. 1. Design of the PUC (a). The PUC is $90 \mathrm{~mm}$ wide and composed of a shallow cylinder of acrylic to which semi-permeable polycarbonate membranes (e.g., $0.4 \mu \mathrm{m}$ poresize) are attached using adhesive. Pressure due to filling does not cause bulging of the membrane. Loading the PUC is conducted via a syringe with Luer-lock fittings (b); the PUC is loaded from below and air displaced by the entry of the solute exits through an empty syringe on the top of the PUC.

alteration or manipulation of the natural water to maximize the environmental relevance of the assays.

\section{Materials and procedures}

Description of the experimental design-The PUC consisted of a rigid polycarbonate ring with a diameter of $7.5 \mathrm{~cm}$ and a height of $1.0 \mathrm{~cm}$ (Fig. 1). The rings are easily produced by slicing polycarbonate pipe. Polycarbonate membrane filters $(0.4$ or $5 \mu \mathrm{m}$, Isopore, Millipore) were glued (acrylic glue) on each side of the disk to allow a maximal surface of exchange between the external solution and the sample (approx. $37 \mathrm{~mL}$ ) inside the PUC (Table 1). A minimum amount of glue is applied with the main concern being that the glue layer is continuous in order to prevent any leakage. Two holes ( $1 \mathrm{~mm}$ diameter) were bored into opposite sides of the ring to install two female $0.8 \mathrm{~mm}$ Luer

Table 1. Physical characteristic of the Porous Underwater Chamber (PUC).

\begin{tabular}{lc} 
Physical parameter & $\begin{array}{c}\text { Polycarbonate } \\
\text { membrane } \\
\text { characteristics }\end{array}$ \\
\hline External diameter $(\mathrm{cm})$ & 7.5 \\
Internal diameter $(\mathrm{cm})$ & 6.9 \\
Membrane thickness $(\mathrm{cm})$ & $10^{-3}$ \\
Membrane surface $(2 \mathrm{sides})\left(\mathrm{cm}^{2}\right)$ & 74.8 \\
Porosity $(\%)$ & $5-20$ \\
Volume $\left(\mathrm{cm}^{3}\right)$ & 37.4 \\
\hline
\end{tabular}


connectors joined to Luer-lock needleless valves (Small Parts). The sample was gently injected using a $60 \mathrm{~mL}$ Luerlock syringe attached to the bottom port. An empty syringe placed at the top of the PUC was used to reduce pressure effects during loading and sampling. To reduce cell adhesion to the internal surface of the PUCs, the biological suspension was consecutively sampled and expulsed three times using a syringe prior to be taken for analysis. In this case, a cell recovery of > 94\% was obtained. Cyanobacterial growth was not affected by a 96$\mathrm{h}$ exposure in the PUCs as compared with growth measured in polycarbonate tubes.

Prior to use, the PUCs were filled and soaked in $0.1 \% \mathrm{HCl}$ for $30 \mathrm{~min}$, rinsed thoroughly with deionized water (Gradient, Millipore) then dried under HEPA laminar flow. All syringes, containers, and membranes were made of polypropylene or polycarbonate and were soaked at least $12 \mathrm{~h}$ in $0.1 \% \mathrm{HCl}$, rinsed seven times with deionized water, dried, and then stored in sealed containers or bags prior to use. Manipulations of the PUC did not result in any detectable iron contamination $(<0.1 \mathrm{nM}$, as measured with a graphite furnace atomic adsorption spectrometer [Perkin Elmer AA600]). Since the reuse of the PUCs did not affect the response of the cyanobacterial bioreporter to variable iron bioavailability (calibration curves in Fraquil, see below), the PUCs were reused up to four times before replacement of their membranes. Before attaching the replacement filters, the surface of the disks were gently sanded to remove any remaining filter and glue with fine-grit sandpaper or emery cloth (150-180 grit), using a gentle circular motion.

In some experiments, the PUCs were suspended in a large volume (20 or $60 \mathrm{~L}$ ) of water using acrylic fishing line that was attached to one of the needleless valves and glued on the outside the containers. In 20-L containers, the water was constantly stirred using a large magnetic stirrer at $300 \mathrm{rpm}$. In 60 -L containers, a submersible pump (Rule $24,1350 \mathrm{~L} \mathrm{~h}^{-1}$ ) was used to stir the water for $15 \mathrm{~min}$ every $30 \mathrm{~min}$.

Equilibration experiments-The time required for the PUCs to equilibrate with an external solution was determined in $20 \mathrm{~L}$ and $60 \mathrm{~L}$ containers using $0.4-2 \mathrm{mg} \mathrm{L}^{-1}$ of Suwannee River Fulvic Acid (SRFA; International Humic Substance Society) or $0.5 \%$ bromophenol blue (BPB, Fluka). The PUCs were filled with an experimental solution (Table 2) then plunged into a solution of similar composition containing the SRFA or BPB. Concentrations inside and outside the PUCs were followed over $25 \mathrm{~h}$. The SRFA was quantified using fluorescence $\left(\lambda_{\text {excitation }}=310-390 \mathrm{~nm} ; \lambda_{\text {emission }}=410-600\right.$ $\mathrm{nm}$; Turner Design, TD 700), and the BPB was measured by absorbance (595 nm; Nova Analytics, Secomam S250). For the experiment with SRFA, each point was acquired in triplicate, and each experiment was repeated three times. Experiments with BPB were repeated twice.

Diffusion of a tracer into the PUCs was evaluated using a 2-box model (inside and outside the PUCs). Diffusion was described by Fick's first law (Eq. 1 and 2), where $C_{\text {in }}$ and $C_{\text {out }}$ are the concentrations of the tracer inside and outside the PUCs $\left[\mathrm{mg} \mathrm{L}^{-1}\right]$ for a given experimental time, $t[\mathrm{~s}] . V_{\text {in }}$ and $V_{\text {out }}$ correspond to the volumes of the PUC and the external container $\left[\mathrm{cm}^{3}\right]$, respectively.

$$
\begin{aligned}
\frac{d C_{\text {in }}}{d t} & =\frac{a \times\left(C_{\text {out }}-C_{\text {in }}\right)}{V_{\text {in }}} \\
\frac{d C_{\text {out }}}{d t} & =\frac{-a \times\left(C_{\text {out }}-C_{\text {in }}\right)}{V_{\text {out }}}
\end{aligned}
$$

The variable $a$ is the diffusive transfer rate of the tracer between the two boxes (Eq. 3). It depends upon $D$, the diffusion coefficient of the tracer $\left[\mathrm{cm}^{2} \mathrm{~s}^{-1}\right], A$, the area of the PUCs through which diffusion occurs $\left[\mathrm{cm}^{2}\right]$, and $L$, the thickness of the polycarbonate membrane of the PUC and its diffusion layer $[\mathrm{cm}]$.

$$
a=\frac{D \times A}{L}
$$

The concentration of tracer inside a PUC that is plunged into an external reservoir can be analytically resolved (Eq. 4) for any given exposure time. $V_{\text {tot }}$ refers to the total volume (sum of $V_{\text {in }}$ and $V_{\text {out }}$ ) and $C_{\mathrm{t}}$ to the concentration of the tracer inside the PUC at time $t, C o_{\text {in }}$ and $C o_{\text {out }}$ to the initial concentrations of the tracer inside and outside the PUC, respectively.

$$
\log \left[\frac{C_{\mathrm{t}} V_{\text {tot }}-C o_{\text {in }} V_{\text {in }}-C o_{\text {out }} V_{\text {out }}}{\left(C o_{\text {in }}-C o_{\text {out }}\right) V_{\text {out }}}\right]=-\frac{A D t V_{\text {tot }}}{L V_{\text {in }} V_{\text {out }}}
$$

For our experimental design, $C o_{\text {in }} \approx 0$ and $V_{\text {out }} \approx V_{\text {tot }}$. In such a case, the diffusion coefficient of any tracer can be simplified as follows:

$$
D=\log \left(\frac{-C o_{\text {out }}}{C_{\mathrm{t}}-C o_{\text {out }}}\right) \times \frac{L V_{\text {in }}}{A t}
$$

Table 2. Composition of experimental solutions. TAP $1 / 8$ (Harris 1989) was used in $60 \mathrm{~L}$ polycarbonate containers whereas Fraquil (Morel et al. 1975) was used in $20 \mathrm{~L}$ polystyrene carboy.

\begin{tabular}{lcc}
\hline Component & $\begin{array}{c}\text { TAP 1/8 } \\
\text { concentration (M) }\end{array}$ & $\begin{array}{c}\text { Fraquil } \\
\text { concentration (M) }\end{array}$ \\
\hline $\mathrm{Ca}^{2+}$ & $2.1 \times 10^{-5}$ & $2.5 \times 10^{-4}$ \\
$\mathrm{~K}^{+}$ & $1 \times 10^{-4}$ & $2 \times 10^{-5}$ \\
$\mathrm{Mg}^{2+}$ & $2.5 \times 10^{-5}$ & $1.5 \times 10^{-4}$ \\
$\mathrm{SO}_{4}{ }^{2-}$ & $2.5 \times 10^{-5}$ & $1.5 \times 10^{-4}$ \\
$\mathrm{PO}_{4}{ }^{3-}$ & $6.3 \times 10^{-5}$ & $2 \times 10^{-5}$ \\
$\mathrm{Cl}^{-}$ & $4.3 \times 10^{-3}$ & $2.5 \times 10^{-4}$ \\
$\mathrm{NH}_{4}{ }^{+}$ & $4.3 \times 10^{-3}$ & -- \\
$\mathrm{NO}_{3}{ }^{-}$ & -- & $1 \times 10^{-4}$ \\
$\mathrm{Na}^{+}$ & -- & $2.5 \times 10^{-4}$ \\
$\mathrm{Acetate}^{-}$ & $1.2 \times 10^{-3}$ & -- \\
$\mathrm{Tris}^{-3}$ & $4.9 \times 10^{-3}$ & -- \\
\hline$/$ & $4.1 \times 10^{-3}$ & $1.6 \times 10^{-3}$ \\
$\mathrm{pH}$ & 5.0 & 6.9 \\
\hline
\end{tabular}


Use of the PUC to determine cadmium bioaccumulation: comparison with bottle assays-A main concern with the PUC (and analogous devices such as organisms retained in dialysis bags) is that elemental fluxes into the system can become limiting and thus nonrepresentative of those occurring in situ (Wilkinson and Buffle 2004). In such a case, measurements would reflect fluxes entering the device and metal complex dissociation fluxes (van Leeuwen 1999) rather than those experienced by organisms exposed exogenously. To maximize the possibility of a diffusive limitation, an organism with a fairly high internalization flux (e.g., Chlamydomonas reinhardtii, $7 \mu \mathrm{m}$ diameter; Kola and Wilkinson 2005), was used to assess Cd bioaccumulation. Biouptake was compared for cells exposed in a PUC that was placed in a $60 \mathrm{~L}$ container and those suspended in $500 \mathrm{~mL}$ experimental solution in a 1-L Erlenmeyer flask. Algae were first grown to mid-exponential growth phase in a diluted (4 fold) TAP medium (Harris 1989; Kola and Wilkinson 2005$)$ at constant temperature $\left(20^{\circ} \mathrm{C}\right)$, agitation (100 rpm), and lighting (12 hours:12 h light:dark cycle, 50 umole photon $\mathrm{m}^{-2} \mathrm{~s}^{-1}$, INFORS incubator). They were then isolated by centrifugation $(7 \mathrm{~min}$. at $2700 \times g$, Heraeus AG Sepatech centrifuge) and rinsed with an experimental solution free of cadmium (Table 2). A suspension of $C$. reinhardtii (Table 2 , TAP 1/8; cell density $=5 \times 10^{5}$ cells $\mathrm{mL}^{-1}$ ) was used to fill the PUCs that were suspended in the $60 \mathrm{~L}$ tanks containing TAP $1 / 8$ and cadmium $\left(3 \times 10^{-6} \mathrm{M}\right.$ Cd buffered with citrate to give $1.4 \times 10^{-7} \mathrm{M} \mathrm{Cd}^{2+}$ based upon MINEQL+, ver. 4.0 with updated thermodynamic constants from NIST 8.0). In parallel, $5 \times 10^{5}$ cells $\mathrm{mL}^{-1}$ were resuspended in an identical (Cd containing) experimental solution in a $500 \mathrm{~mL}$ Erlenmeyer flask. Under these experimental conditions, Cd membrane transporters are only half-saturated (Kola and Wilkinson 2005). In both cases, biouptake experiments were performed under ambient light (28 $\mu \mathrm{mol}$ photon $\mathrm{m}^{-2} \mathrm{~s}^{-1}, 12 \mathrm{~h}: 12 \mathrm{~h}$ light:dark cycling) and temperature $\left(20-22^{\circ} \mathrm{C}\right)$. Cell densities, dissolved $\mathrm{Cd}$, free $\mathrm{Cd}$, and intracellular Cd were measured over $23 \mathrm{~h}$. For each experimental time point, $50 \mathrm{~mL}$ of the algal solution from the flasks or the entire $37 \mathrm{~mL}$ content of a PUC was filtered over a $5 \mu \mathrm{m}$ polycarbonate membrane (Millipore). The filtrate was collected to determine dissolved Cd by ICP-MS (Hewlett Packard 4500 Series), and free cadmium was measured using an ion selective electrode (Orion 96-48). Intracellular cadmium was evaluated by washing filtered algae (3 times with $5 \mathrm{~mL}$ of 5 $\mathrm{mM}$ EDTA, total washing time of $1 \mathrm{~min}$, and then once with the experimental solution without $\mathrm{Cd}$ ) before digestion in 300 $\mu \mathrm{L}$ concentrated ultrapure nitric acid (JT Baker; $90^{\circ} \mathrm{C}, 1 \mathrm{~h}$ ). The Cd internalization flux $\left(J_{\text {int }}\right)$ was determined from the slope of intracellular cadmium with time after normalization for cell surface areas that were determined by an electronic particle counter (Coulter Multisizer II, $50 \mu \mathrm{m}$ aperture, Beckman Coulter). For each experimental (time) point, a PUC was sampled for each of the membrane pore sizes (i.e., 0.4 or $5 \mu \mathrm{m}$ polycarbonate membranes). Experiments were performed in triplicate.
Use of the PUC with an iron bioreporter-comparison with polycarbonate tube assays-The iron bioreporter used in these experiments is a genetically modified cyanobacterium (Synechococcus PCC 7942, Porta et al. 2003) with an average estimated spherical diameter of $0.7 \mu \mathrm{m}$. Prior to use, the bioreporter was acclimated to a slight iron deficiency (Hassler et al. 2006) at the concentration of Fe found in the Fraquil medium $\left(-\log \left[\mathrm{Fe}^{3+}\right]=19.9,\left[\mathrm{Fe}^{\prime}\right]=19 \mathrm{pM}\right.$; Morel et al. 1975; Hassler and Twiss 2006). In this case, a slight iron deficiency is defined as a concentration of bioavailable iron that is both sufficiently high to avoid any significant expression of bioluminescence and low enough for the bioreporter not being able to build a significant intracellular iron reserve (see Hassler et al. 2006). Experiments were conducted in an incubation chamber (Percival Scientific) using $100 \mathrm{rpm}$ rotary shaking at $19^{\circ} \mathrm{C}$ and constant illumination of $60 \mu \mathrm{mol}$ photons $\mathrm{m}^{-2} \mathrm{~s}^{-1}$. The bioreporter was collected by filtration $(0.4 \mu \mathrm{m}$ polycarbonate filter, Millipore) from its early to mid exponential growth phase. Cells were washed in $10^{-5} \mathrm{M}$ EDTA for $1 \mathrm{~min}$, rinsed three times with Fraquil medium (Table 2), and then resuspended in a small volume of Fraquil medium. An initial cell density of $10^{5}$ cyanobacteria per milliliter was obtained by diluting the concentrated suspension into a larger volume that was subsequently used to fill the PUCs or $30 \mathrm{~mL}$ polycarbonate tubes.

Cell densities were measured with an electronic particle counter (Coulter Multisizer 3, $30 \mu \mathrm{m}$ aperture, Beckman Coulter). Chlorophyll $a$ was determined fluorimetrically (Turner Designs TD 700) following extraction in 90\% acetone (Welschmeyer 1994). Since the polycarbonate membranes used in the PUCs attenuate the light 1.7-fold (Luminometer LI-Cor model LI-188B), and light affects iron bioavailability sensed by the bioreporter (Hassler et al. 2006), the PUCs were incubated (Percival Scientific) at $100 \mu \mathrm{mol}$ photons $\mathrm{m}^{-2} \mathrm{~s}^{-1}$ so that the cells would be exposed to a constant $60 \mu \mathrm{mol}$ photons $\mathrm{m}^{-2} \mathrm{~s}^{-1}$.

In a first set of experiments, the bioreporter was exposed to low $\left(10^{-9} \mathrm{M}\right)$ and high $\left(10^{-7} \mathrm{M}\right)$ total iron concentrations for 12 h. Exposures were performed in PUCs suspended in a $20 \mathrm{~L}$ polycarbonate carboy or directly in tubes filled with the same experimental medium. In the low and high iron solutions, the free ion concentrations of all other trace metals were not allowed to vary (Hassler and Twiss 2006; Hassler et al. 2006). Since the bioreporter required $12 \mathrm{~h}$ to fully respond to bioavailable iron (Hassler et al. 2006), a second set of experiments was performed in both the PUCs and the polycarbonate tubes for incubation times ranging from 10 to $22.5 \mathrm{~h}$. In that case, Fraquil medium, with total iron concentrations of $10^{-8} \mathrm{M}$, was used in both the test tubes and the 20-L container. Iron bioavailability was reduced by adding $1 \mu \mathrm{M}$ of either SRFA or the siderophore Desferrioxamine B (DFB, Sigma Aldrich). Since solutions inside and outside the PUCs were not identical, equilibration of the bioreporter could be evaluated.

After exposure to iron, the response of the bioreporter was measured by cellular bioluminescence (Femtomaster FB14 luminometer, Berthold Detection Systems, GmbH) following 


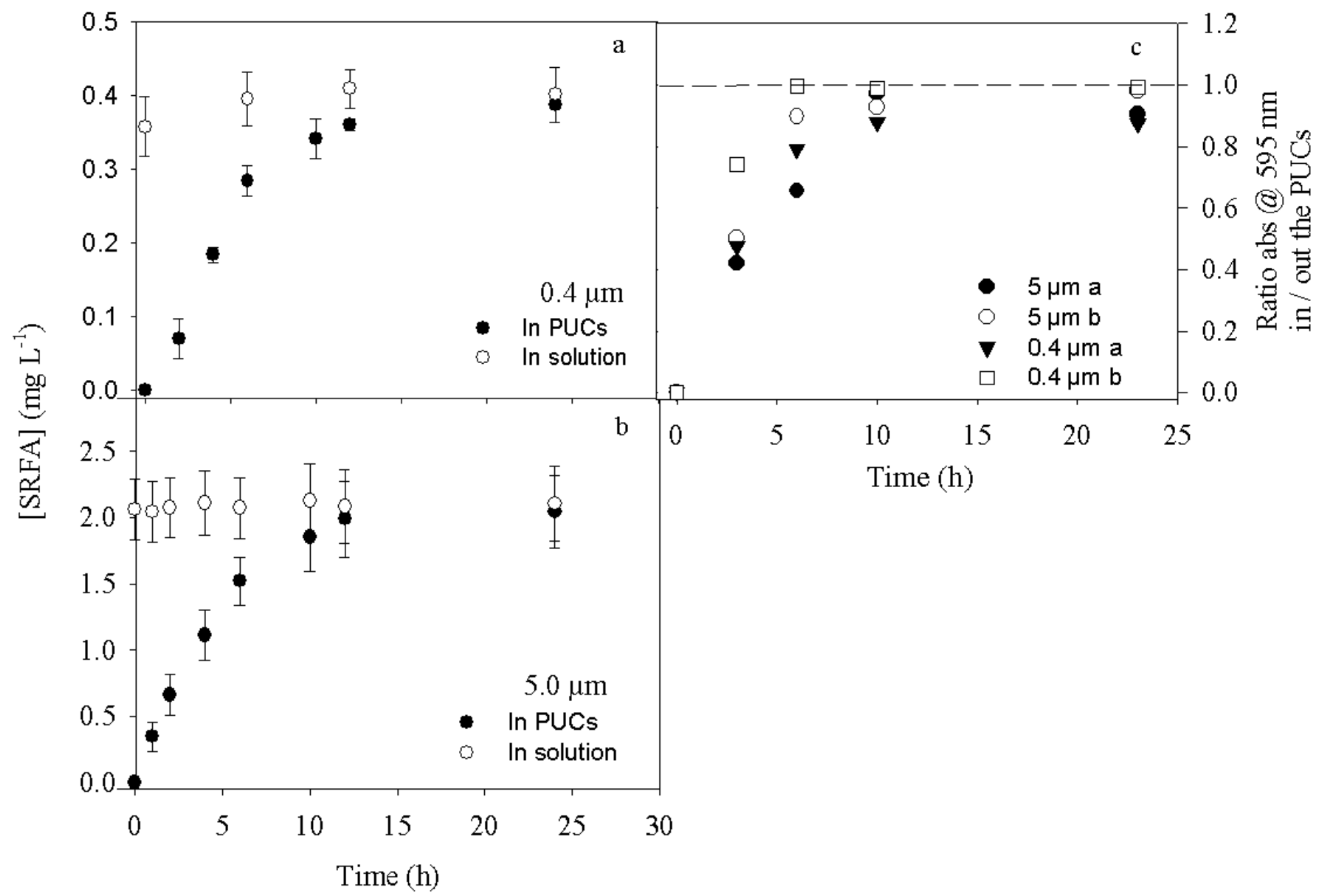

Fig. 2. Equilibration of PUC with SRFA ( $a$ and $b$ ) and BPB (c) as a function of poresize. Initially, the PUCs were filled with Fraquil medium and plunged into $20 \mathrm{~L}$ of Fraquil medium containing SRFA ( $a$ and b) or filled with experimental solution and plunged into $60 \mathrm{~L}$ of experimental solution containing BPB (c). The concentrations of SRFA and BPB were determined inside the PUCs and in the external solution as a function of time. The dashed line represents the concentration of BPB outside the PUCs. Error bars represent standard deviations $(n=3)$. In (c), the experiment was repeated twice, and all data are shown.

the addition and reaction ( 5 min, dark) of $3 \mu \mathrm{L}$ of $\mathrm{n}$-decyl aldehyde (Sigma Aldrich) to $1.5 \mathrm{~mL}$ of the biological suspension to give a final concentration of $60 \mu \mathrm{M}$ (Hassler et al. 2006). Each data point was gathered in triplicate, and each experiment was performed in triplicate. The response of the bioreporter to total iron $\left(4.5 \times 10^{-7}\right.$ to $\left.2.8 \times 10^{-10} \mathrm{M}\right)$ was verified and calibrated (duplicate measurements) in the Fraquil medium. In addition to $\mathrm{Fe}^{3+}$, all major Fe species present in the Fraquil medium (e.g., Fe-bound to EDTA) are thought to contribute to the bioavailable iron pool (Hassler and Twiss 2006).

In a third set of experiments, the bioreporter was exposed to filtered $(<0.4 \mu \mathrm{m}, \mathrm{FW})$ lakewater in the PUCs and in test tubes and to whole (WW) lake water (PUCs only) sampled from a depth of $5 \mathrm{~m}$ from the pelagic zone of Lake Erie at Stations 23, 84, and 357 (see Twiss et al. 2000 for location and description). Sampling was performed in July 2004 onboard the C.C.G.S. Limnos. To assess the contribution of particulate iron to the bioavailable Fe pool, the bioreporter was resuspended in PUCs containing filtered lakewater, and then incu- bated in a 20-L carboy filled with either filtered lakewater or whole lakewater. To mimic in situ exposure, the carboys were placed in an on deck incubator consisting of an acrylic container covered with neutral density screens to reduce the ambient photon flux by $75 \%$. They were maintained at $20^{\circ} \mathrm{C}$ using a constant flow of surface lakewater. In parallel, at each station, the bioreporter was added to filtered lakewater in test tubes, sealed with parafilm, then kept: (i) in plastic bags in the on deck incubator (90-300 $\mu \mathrm{mol}$ photons $\left.\mathrm{m}^{-2} \mathrm{~s}^{-1}\right)$ or (ii) in incubation chambers (Percival Scientific) at $20^{\circ} \mathrm{C}$ and $60-70 \mu \mathrm{mol}$ photons $\mathrm{m}^{-2} \mathrm{~s}^{-1}$ ). These controls were designed to verify whether cells in the tubes, and the PUCs responded similarly to filtered lakewater and to assess the impact of the light source, i.e., natural light (minus the ultraviolet component filtered by polycarbonate containers) versus fluorescent light. Each measurement was performed in triplicate. The response of the bioreporter to iron was also calibrated in the Fraquil medium, as described above. Since the cellular Chl $a$ content of the bioreporter was constant $\left(15 \pm 4 \mathrm{fmol} \times\right.$ cell $^{-1}$; Hassler et 


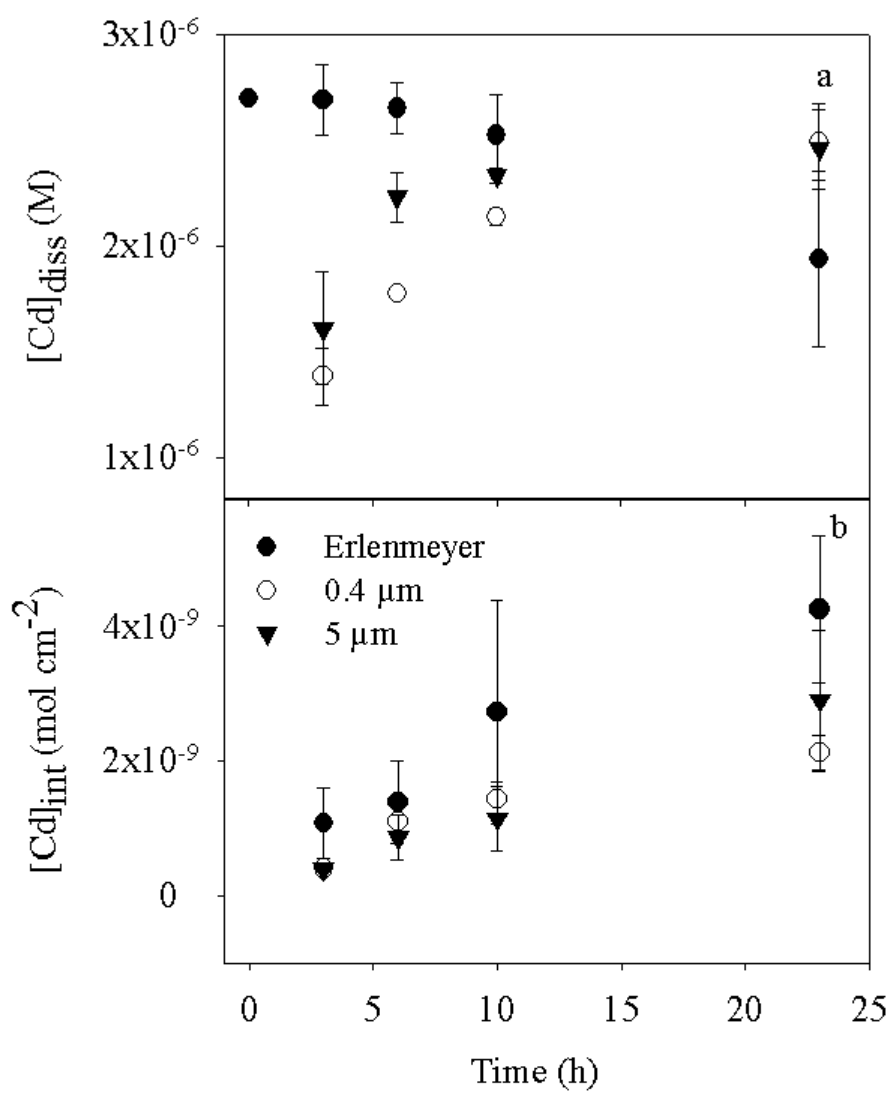

Fig. 3. Comparison of the bioaccumulation in PUC (suspended in $60 \mathrm{~L}$ ) and in an Erlenmeyer flask for experiments performed with Chlamydomonas reinhardtii in $1.4 \times 10^{-7} \mathrm{M} \mathrm{Cd}^{2+}$. Average dissolved $\mathrm{Cd}$ (a) and internalized $\mathrm{Cd}(\mathrm{b})$ were measured for $23 \mathrm{~h}$ exposures $(n=3)$. Cells were exposed to laboratory lighting $\left(28 \mu \mathrm{mol}\right.$ photon $\mathrm{m}^{-2} \mathrm{~s}^{-1}, 12 \mathrm{~h}: 12 \mathrm{~h}$ light:dark cycling) and temperature $\left(20^{\circ} \mathrm{C}-22^{\circ} \mathrm{C}\right)$.

al. 2006), bioluminescence was normalized by the cellular Chl $a$ content. To verify whether grazing was occurring in whole lakewater in which the PUCs were exposed, Chl $a$ was measured in the external solution of the carboy. An absence of iron contamination was verified by GFAAS.

\section{Assessment}

Chemical equilibration within the PUC-To avoid zooplankton grazing and particle sedimentation, water inside the PUCs was filtered prior to deployment in the whole water. Since the filtration used the same membrane size as that used to construct the PUCs, the dissolved fraction (filtered lakewater) should initially be identical on the inside and outside the PUCs in the in situ experiments. Nonetheless, to probe the effect of a perturbation (e.g., due to biological consumption), equilibration experiments were performed using SRFA or BPB as external diffusive probes in a synthetic water (Table 2). Regardless of the membrane pore size, the concentration of probe inside the PUCs and in the external solution was statistically equal (Student $t$ test, $P>0.05$ ) after $10 \mathrm{~h}$ (Fig. 2). Equilibration times were similar for the SRFA (Fig. 2a and 2b) and BPB (Fig. 2c) despite the fact that the compounds and experimental set-up were different (20 versus $60 \mathrm{~L}$ containers, different mixing speeds, different molar masses and ionic charges of the solutes: BPB: $670 \mathrm{~g} \mathrm{~mol}^{-1}$, SRFA ca. $1650 \mathrm{~g} \mathrm{~mol}^{-1}$; Leenheer et al. 1995; Lead et al. 2000). The observed initial increase of SRFA in the PUCs (first $6 \mathrm{~h}$ of Fig. $2 \mathrm{a}, 2 \mathrm{~b}$ ) was used to calculate an effective diffusion coefficient for the SRFA ( $D_{\mathrm{SRFA}}$, Eq. 5). Due to the existence of a diffusive layer on both sides of the polycarbonate membrane, the diffusion layer in Eq. $5\left(1.1 \times 10^{-2} \mathrm{~cm}\right)$ was taken to be equal to the sum of the membrane thickness $\left(10^{-3} \mathrm{~cm}\right.$, Table 1$)$ and an unstirred layer $\left(5 \times 10^{-3} \mathrm{~cm}\right)$ on each side of the membrane (Whitfield and Turner 1979; Wilkinson and Buffle 2004). The surface area of the PUCs, $A\left(9.35 \mathrm{~cm}^{2}\right)$ took into account the average porosity of the polycarbonate membrane (Table 1). For both the 0.4 and $5 \mu \mathrm{m}$ membranes, $D_{\text {SRFA }}$ values of $(2.0 \pm 0.2) \times 10^{-6} \mathrm{~cm}^{2} \mathrm{~s}^{-1}$ were determined (Eq. 5), in good agreement with $D_{\text {SRFA }}$ values of $2.7 \times 10^{-6} \mathrm{~cm}^{2} \mathrm{~s}^{-1}$ measured in water (ionic strength of $5 \mathrm{mM}$ at $\mathrm{pH}$ 7; Lead et al. 2000). The determination of similar values of $D_{\text {SRFA }}$ for the different membrane pore sizes supports the contention that the transport of environmentally relevant small molecules, such as the SRFA, would not be limited by external transport considerations. The slight lower value of $D_{\text {SRFA }}$ that was evaluated here is likely not significant given the precision on each of the parameters in Eq. 5, however, if real could be attributed to tortuousity or obstructive effects of the membrane.

Cd bioaccumulation by C. reinhardtii-Bioaccumulation was compared for PUCs suspended in $60 \mathrm{~L}$ of $1.4 \times 10^{-7} \mathrm{M} \mathrm{Cd}^{2+}$ and flasks. At 6,10 , and $23 \mathrm{~h}$, the $\mathrm{Cd}^{2+}$ concentration inside the PUCs (as measured by the Cd selective electrode) was constant and equal to that of the external solution $(60 \mathrm{~L})$ (data not shown). Total dissolved Cd was completely equilibrated for times exceeding $10 \mathrm{~h}$ (Fig. 3a), in agreement with the equilibration times determined above. Considering that the diffusion coefficients of aqueous Cd species (small complexes and free ion) are generally larger than the SRFA and that the Cd biouptake flux by the organisms is low compared to the diffusive supply into the PUCs (see below), the results support the contention that the use of the PUCs does not shift the rate-limiting step away from biouptake. Note that following a 23-h exposure, an average $29 \%$ depletion of dissolved Cd was seen in the Erlenmeyer flask, whereas no decrease was measured in the PUCs suspended in the $60 \mathrm{~L}$ container. This observation highlights one of the advantages of the PUCs to follow long-term bioaccumulation or toxicity, especially for the low concentrations of trace elements that are often found in natural waters.

For algae incubated in both the Erlenmeyer flasks and the PUCs, Cd uptake increased linearly with time. A mean internalization flux of $16.1 \pm 2.9 \mathrm{pmol} \mathrm{Cd} \mathrm{cm}^{-2} \mathrm{~h}^{-1}(19.3,15.2$ and $\left.13.8 \mathrm{pmol} \mathrm{Cd} \mathrm{cm}{ }^{-2} \mathrm{~h}^{-1}\right)$ was observed for the flasks; $14.7 \pm$

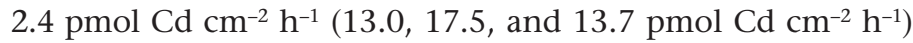
for the PUC with the $5 \mu \mathrm{m}$ membrane and $13.8 \pm 5.5 \mathrm{pmol} \mathrm{Cd}$ $\mathrm{cm}^{-2} \mathrm{~h}^{-1}\left(19.7,12.7\right.$, and $\left.8.95 \mathrm{pmol} \mathrm{Cd} \mathrm{cm}^{-2} \mathrm{~h}^{-1}\right)$ for the PUC 
[Fe] bioavailable (M)

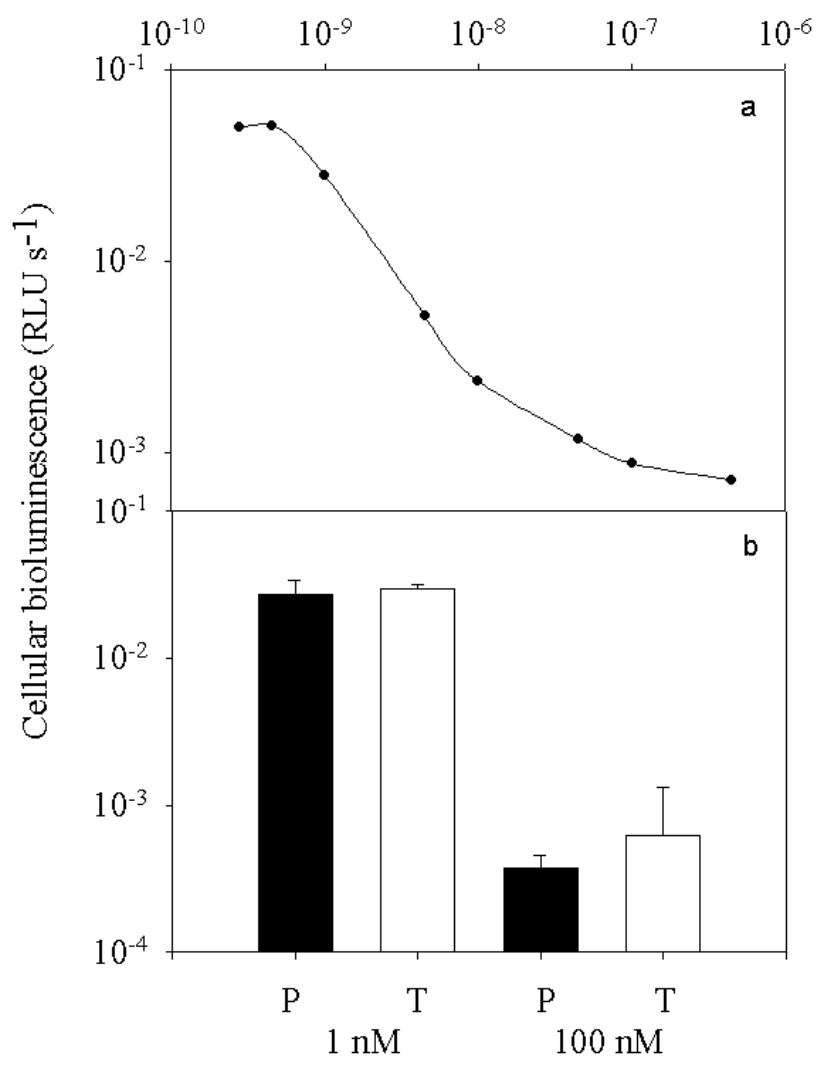

Fig. 4. Typical response (expressed as cellular bioluminescence) of the bioreporter to iron bioavailability in the Fraquil medium (a). Comparison of the cellular bioluminescence in response to high (100 nM) and low (1 nM) iron bioavailability in Fraquil medium (b) for exposures in $20 \mathrm{~mL}$ tubes ( $T$ ) and in the Porous Underwater Chamber ( $P$ ). Exposures were performed at $60 \mu \mathrm{mol}$ photons $\mathrm{m}^{-2} \mathrm{~s}^{-1}$ at $19^{\circ} \mathrm{C}$. Error bars represent standard deviations $(n=3)$. with the $0.4 \mu \mathrm{m}$ membrane (Fig. 3b). For the conditions examined here, Cd internalization fluxes were well below calculated maximum diffusive fluxes of free cadmium in solution (Kola and Wilkinson 2005). Internalization fluxes did not appear to be significantly affected by performing exposures in the PUCs, again suggesting that biological uptake and not the diffusive supply of Cd was rate-limiting. This is an important result since shifts in the rate-limiting flux could modify the bioavailable $\mathrm{Cd}$ species, i.e., in contrast to the biologically limited case, when diffusion is rate-limiting, labile metal complexes may become bioavailable to the algae (van Leeuwen 1999; Wilkinson and Buffle 2004). The roles of ligands, competing ions, $\mathrm{pH}$, etc. on trace metal bioavailability can only be correctly reflected in situ if the use of the PUC does not change the nature of the rate-limiting step describing the interactions between microorganisms and pollutants.

Comparison of the bioreporter response in the PUC and polycarbonate tubes - In test tubes filled with Fraquil medium, a decrease in the cellular bioluminescence (RLU s ${ }^{-1}$ cell $^{-1}$ ) was observed when the concentration of iron increased from $0.45 \mathrm{nM}$ to $45 \mathrm{nM}$, indicating an increased iron bioavailability (for this bioreporter, bioluminescence decreases as bioavailable iron concentration increases, Fig. 4a). Iron bioavailability $\left([\mathrm{Fe}]_{\text {bio }}\right.$ ) was best described by $\log ($ cellular bioluminescence $)=-0.87 \log \left([\mathrm{Fe}]_{\text {bio }}\right)-9.94\left(r^{2}=0.97\right)$. A similar response (Student $t$ test, $P>0.05$ ) was observed in tubes and in PUCs for bioreporters that were exposed to 1 or $100 \mathrm{nM}$ bioavailable iron (Fig. 4b). The similarity of responses in the PUCs and tubes suggests that the deployment of the bioreporter in the PUCs is representative of both laboratory and in situ exposures.

Bioluminescence was also verified for tubes and PUCs that were exposed to a Fraquil medium spiked with $10 \mathrm{nM}$ Fe in the presence of either SRFA or DFB (Fig. 5a and b). In this set of

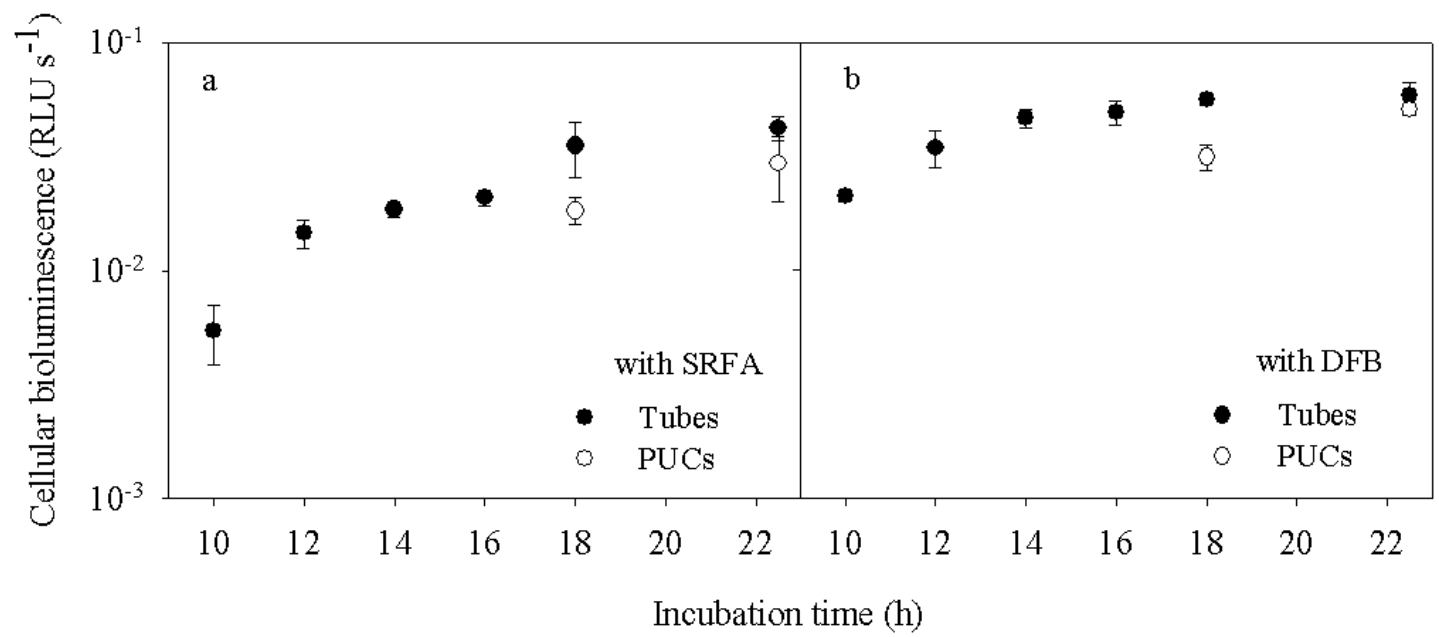

Fig. 5. Dynamics of the response of the bioreporters in test tubes and in PUCs. Cellular bioluminescence was followed over $22.5 \mathrm{~h}$ in Fraquil medium with $10 \mathrm{nM}$ Fe and $1000 \mathrm{nM}$ of an organic chelating agent (SRFA, a; DFB, b). Initially, PUCs were filled with Fraquil medium without chelating agent. The exposures were performed using $60 \mu \mathrm{mol}$ photons $\mathrm{cm}^{-2} \mathrm{~s}^{-1}$ at $19^{\circ} \mathrm{C}$. Error bars represent standard deviations $(n=3)$. 

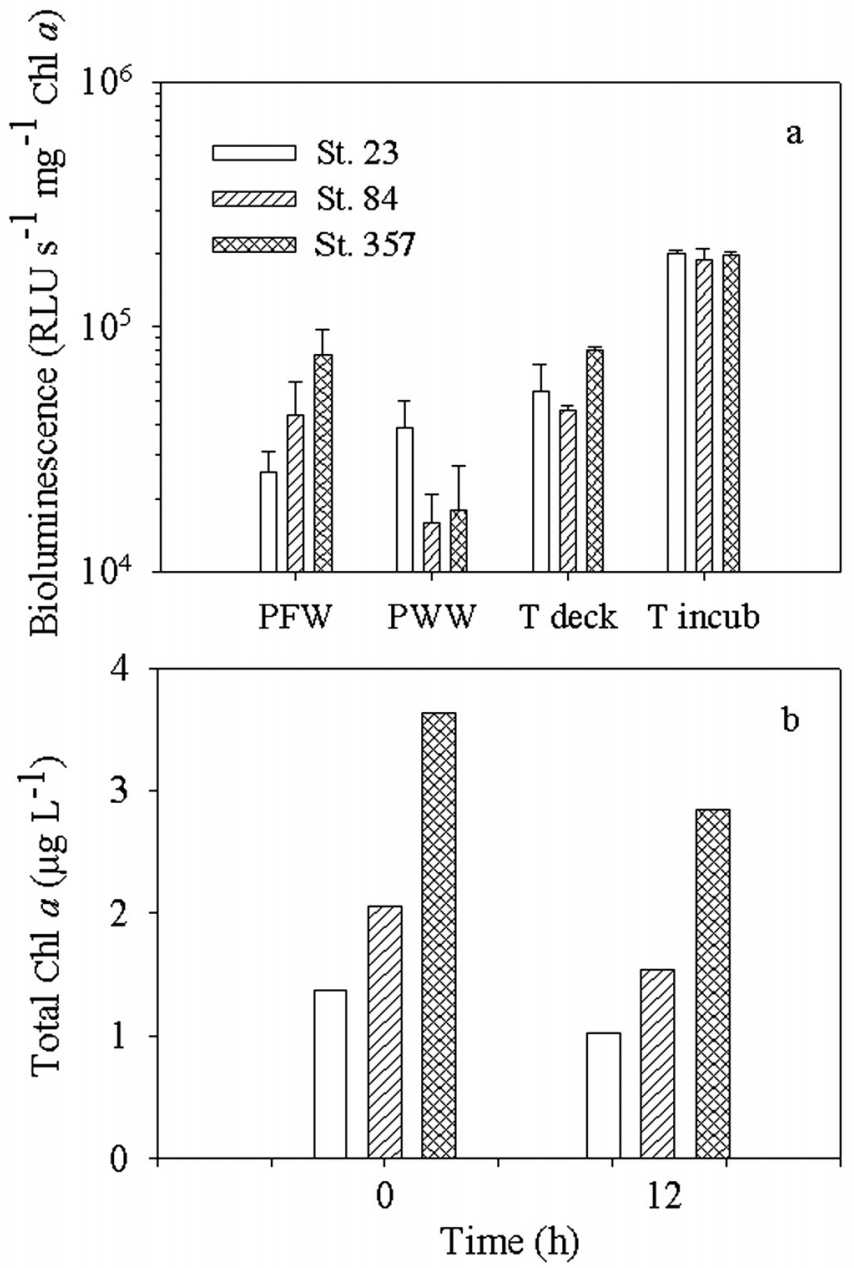

Fig. 6. Details of the carboy experiments in the on deck incubator of the C.C.G.S. Limnos, Lake Erie (July 2004, Station 23, 84, and 357). The response of the bioreporter (a) was measured in various conditions (tubes $[T]$ versus PUC $[\mathrm{P}]$; incubator chambers [incub] versus on deck incubation; filtered $0.45 \mu \mathrm{m}[\mathrm{FW}]$ versus whole lakewater [WW]) following a $12 \mathrm{~h}$ exposure at $20^{\circ} \mathrm{C}$. Error bars represent standard deviations $(n=3)$. Total $\mathrm{Chl} a$ in the carboy filled with whole water (b) before and after exposure to the bioreporter.

experiments, the initial solutions inside (10 nM Fe) and outside (10 nM Fe + ligand) the PUCs were different. The bioreporter was also directly exposed to $10 \mathrm{nM}$ Fe in presence of either SRFA or DFB in the polycarbonate tubes. Experiments were performed for exposure times of $<24 \mathrm{~h}$ in order to avoid major chemical and biological influences on the iron status (Hassler et al. 2006). Both the PUCs and the polycarbonate tubes had similar bioreporter responses with increased cellular bioluminescence occurring with increased exposure times (Fig. 5). Nonetheless, the responses observed in the PUCs appeared to be lower than those observed in the tubes. The lower response was attributed to the delay required for the ligand to diffuse into the disk, to reduce iron bioavailability and to increase the luminescence of the bioreporter. In this experimental protocol, such a problem could be avoided by initially filling the PUCs with filtered water. In addition, since light is required for the expression of bioluminescence (Hassler et al. 2006), in situ incubations would best be started early in the morning to ensure that the bioluminescence assay is performed during the daylight hours.

The outer membrane of the PUC removes particulate metals from the assays. From the literature, it is currently unclear whether these compounds would be bioavailable in situ. For example, several laboratory studies have demonstrated the ability of plankton to directly or indirectly (siderophores) use particulate or colloidal iron (Yoshida et al. 2002; Yoshida et al. 2006). In addition, the biological cycling of trace metals can greatly influence their bioavailability in natural open systems (Twiss and Campbell 1998; Twiss et al. 1996). For example, the biological cycling of iron has been reported to provide $40 \%$ to $80 \%$ of the bioavailable iron in a surface seawater (Price and Morel 1998, McKay et al. 2005). To test this potential effect, two 20 L carboys were prepared containing either an unfiltered or a filtered $(0.45 \mu \mathrm{m})$ natural water sample. The bioreporter was injected into the PUCs containing the filtered water and then incubated in the carboys at the temperature of the lake $\left(20^{\circ} \mathrm{C}\right)$. Measured Fe concentrations were higher in the whole water than what was observed in the filtered water (e.g., Station 84; 30.1 $\pm 4.2 \mathrm{nM}$ Fe in whole lakewater, $5.2 \pm 0.1 \mathrm{nM}$ Fe in filtered lakewater, $n=6$ ). Except for Station 23, the bioreporter showed a significantly higher Fe bioavailability (i.e., lower cellular bioluminescence) in PUCs that were exposed to whole lakewater as compared with those in the filtered lakewater (Fig. 6a). This suggests that some of the iron associated with the particles was bioavailable, likely due to Fe dissociation from particulate Fe rather than the passage of particulate iron through the PUC membrane. In the carboy filled with whole lakewater, the $\mathrm{Chl} a$ content decreased during incubation, suggesting that some grazing by zooplankton and iron cycling was occurring (Fig. 6b). Previous studies have shown that iron species released during grazing (e.g., Hutchins et al. 1999) and insoluble iron (e.g., Naito et al. 2005) could be bioavailable to phytoplankton. Similar concentrations of dissolved iron were measured initially (e.g., $5.2 \pm 0.1 \mathrm{nM}, n=6$ for station 84) and inside the PUCs following $12 \mathrm{~h}$ of exposure to filtered lakewater (e.g., $5.4 \pm 1.8 \mathrm{nM}, n=6$ for station 84 ), demonstrating that no contamination had occurred during the experiment. Nonetheless, the influence of the iron particles was hard to quantify precisely because of the low levels of cellular bioluminescence. No iron limitation (detected by high bioluminescence, see Fig. 6a) could be seen at any of the three Lake Erie stations, as observed previously (Porta et al. 2005). Similar responses were observed when the bioreporter was exposed to filtered lakewater in tubes with respect to the PUCs, suggesting that the exposure in the PUCs did not result in any artifact in the Lake Erie filtered water. Light quality significantly affected the iron bioavailability sensed by the bioreporter (see Hassler et al. 2006 for further details); natural 
light (no UV, on deck incubation) induced an enhanced iron bioavailability (i.e., lower bioluminescence). This observation is in agreement with the known increase in iron internalization that occurs following the photodegradation of some organically bound iron forms (e.g., Maldonado et al. 2005). The effect of biological cycling, particulate Fe pools and light on Fe availability are clearly important problems that demonstrate the need for in situ exposure devices, such as the PUC.

\section{Comments}

The PUC has good potential for use for in situ bioavailability or toxicity experiments using microorganisms. The use of the PUCs is not limited to the biological uptake of trace metals. This parameter was chosen because it is highly sensitive to changes in the diffusive fluxes and thus the measurement facilitated the quantitative assessment of the PUCs by taking biological, chemical, and physical considerations into account. The similarity of the diffusion results obtained for membranes of different pore sizes suggest that the PUCs could be used in field deployments using a number of different microorganisms. Although the requirement for a relatively fast mass transport of both iron and cadmium have been confirmed here, it is, nonetheless, an important point that should be verified prior to any in situ deployment. For experiments involving trace metals in surface waters, biological uptake fluxes are often several orders of magnitude lower than calculated mass transport fluxes (Slaveykova and Wilkinson 2005) and thus transport into the PUC is unlikely to be rate-limiting. For example, for $\mathrm{Cd}$, bioaccumulation fluxes were shown to be two orders of magnitude lower than the maximal diffusive supply (Kola and Wilkinson 2005), such that no limitation would be expected to occur in the PUC, even for very low concentrations of cadmium. For essential metals, such as $\mathrm{Zn}$, where internalization may already be limited by the diffusive flux of the metal (Hassler and Wilkinson 2003), the use of the PUCs would result in a significant additional diffusive barrier. Rapidly bioaccumulating compounds such as inorganic phosphate and certain hydrophobic contaminants will likely be limited by their transport into the PUC, resulting in a potential shift of the chemical equilibria and a biological or chemical signal that does not necessarily represent what the organism would experience in situ. For other compounds (e.g., Fe), exchange with particulate or colloidal forms might be important. In that case, rapidly dissociating (i.e., labile) forms of the compound might be accessible to the organism, as was observed here.

\section{Recommendations}

Exposure of monocultures of microorganisms to field conditions is, by nature, somewhat operational (or arbitrary). Any device that is designed to keep microorganisms in will necessarily keep some particles out. This is a limitation of the device, especially for exposures where particulate or colloidal compounds may play an important role. Although the device was shown to be suitable for evaluating Fe or Cd bioavailability for the experimental conditions that were tested, it is important that the device itself does not significantly reduce biouptake fluxes by the sensing organism. In this respect, further improvements to reduce any possible diffusion limitation could be made as follows:

For a given solute concentration $(x \mathrm{M})$ in the external solution, and for an acceptable equilibration accounted for by $C_{\text {in }}=0.99 \times C_{\text {out }}$, the maximal uptake flux that can occur for a non diffusion-limited situation can be predicted by Eq. 5. For example, for a metal ion with a diffusion coefficient of $7 \times 10^{-6}$ $\mathrm{cm}^{2} \mathrm{~s}^{-1}$ (close to $D_{\mathrm{Cd}}{ }^{2+}$, equilibration time $=3.45 \mathrm{~h}, \mathrm{Eq} .5$ ) and no diffusion limitation for $J_{\text {int }} \leq 0.3 \times J_{\text {diff }}$, biouptake inside the PUC would need to be lower than $0.087 \times \mathrm{mol} \mathrm{h}^{-1}$. Since the cellular biouptake flux should be constant for all of the cells present inside the PUC, the use of a lower biomass could ensure that depletion does not occur (while simultaneously raising detection limits). For metals with biological uptake close to their maximal diffusive supply in solution (e.g., Zn and Fe; Hudson and Morel 1990; Hassler and Wilkinson 2003; Hassler and Twiss 2006), consumption in the PUCs will decrease in direct proportion to the biomass that is employed whereas the diffusive supply will remain unchanged. Stirring the water inside the PUC could be helpful to reduce the diffusive layer thickness and thus increase fluxes. For cases of limiting diffusive fluxes, this more technically challenging improvement would be expected to improve biouptake.

Based on the result of this study, the use of the PUCs would also be promising for longer exposures such as for acute or chronic toxicity tests in situ. Membrane fouling was not examined here but could be a problem (see Buffle et al. 1992), especially for long-term exposures such as the $96 \mathrm{~h}$ exposures that are often used for acute toxicity tests. In that case, the adsorption of organic material to the PUCs would change its apparent charge, binding affinity, and diffusive properties. Under those conditions, the PUCs should not be reused and choice of materials used to construct the PUC becomes even more critical. For example, polyvinylidene fluoride membranes (PVDF) are known to limit the adsorption of natural materials (as compared to nitrocellulose and nylon membranes, e.g., protein adsorption, see www.millipore.com) and thus they might be more appropriate for long-term deployments, especially in eutrophic waters. Nonetheless, PVDF membranes are 12.5-fold thicker than the polycarbonate membrane that was used, which would necessarily increase the time required to equilibrate the PUC. Since similar equilibration times were obtained for 0.4 and $5 \mu \mathrm{m}$ membranes, the use of membranes with higher porosity, e.g., mixed cellulose esters (79\%) or PVDF (80\%) should not affect the equilibration of the PUC with the external solution. On the other hand, the use of materials with extremely small pore sizes $(<10 \mathrm{~nm})$ such as dialysis bags is much more likely to cause an important diffusion limitation. Note that polycarbonate membranes have the advantage of being thin, having a homogenous pore size and containing low levels of trace metal contamination 
(as compared to nitrocellulose membranes, for example).

The PUC are currently too fragile to be employed in situ from the deck of a large ship or even directly deployed on a buoy, although this limitation is less important for deployments in quiescent waters. For example, it would be possible to place the PUCs inside a transparent protective box that allows water and light to enter but protects the devices from turbulence, flotsam, and fish.

\section{References}

Ahner, B. A., J. G. Lee, N. M. Price, and F. M. M. Morel. 1998. Phytochelatin concentrations in the equatorial Pacific. Deep-Sea Res. I 45:1779-1796.

Armbrust, E. V., and others. 2004. The genome of the diatom Thalassiosira pseudonana: Ecology, evolution, and metabolism. Science 306:79-86.

Binnewies, T. T., and others. 2006. Ten years of bacterial genome sequencing: comparative-genomics-based discoveries. Funct. Integr. Genomics 6:165-185.

Buffle, J., D. Perret, and M. Newman. 1992. The use of filtration and ultrafiltration for size fractionation of aquatic particles, colloids, and macromolecules, p. 171-230. In J. Buffle and H. P. van Leeuwen [eds.], Environmental particles. Lewis Publishers.

Dokulil, M. T. 2003. Algae as ecological bio-indicators, p. 285327. In Trace metals and other contaminants in the environment, Vol. 6, Bioindicators and biomonitors-principles, concepts and applications. Elsevier.

Durrieu, C., I. Bradeddine, and C. Daix. 2003. A dialysis system with phytoplankton for monitoring chemical pollution in freshwater ecosystems by alkaline phosphatase assay. J. Appl. Phycol. 15:289-295.

Forrester, G. E. 2005. A field experiment testing for correspondence between trace elements in otoliths and the environment and for evidence of adaptation to prior habitats. Estuaries 28:974-981.

Furnas, M. J. 1991. Net in situ growth rates of phytoplankton in an oligotrophic, tropical shelf ecosystem. Limnol. Oceanogr. 36:13-29.

- 1982. An evaluation of two diffusion culture techniques for estimating phytoplankton growth rates in situ. Mar. Biol. 70:63-72.

Harris, E. H. 1989. Culture and storage methods, The Chlamydomonas sourcebook-a comprehensive guide to biology and laboratory use. Academic Press.

Hassler, C. S., and M. R. Twiss. 2006. Bioavailability of iron sensed by a phytoplanktonic Fe-bioreporter. Environ. Sci. Technol. 40:2544-2551.

— — - R. M. L. McKay, and G. S. Bullerjahn. 2006. Optimization of iron-dependent cyanobacterial (Synechococcus, Cyanophyceae) bioreporters to measure iron bioavailability. J. Phycol. 42:324-335.

- and K. J. Wilkinson. 2003. Failure of the biotic ligand and free-ion activity models to explain zinc bioaccumulation by Chlorella kesslerii. Environ. Toxicol. Chem. 22:620-626.
Hudson, R. J. M., and F. M. M. Morel. 1990. Iron transport in marine phytoplankton: kinetics of cellular and medium coordination reactions. Limnol. Oceanogr. 35:1002-1020.

Hutchins, D. A., A. E. Witter, A. Butler, and G. W. Luther III. 1999. Competition among marine phytoplankton for different chelated iron species. Nature 400:858-861.

Intwala, A, T. D. Patey, D. M. Polet and M. R. Twiss. 2008. Nutritive substitution of zinc by cadmium and cobalt in phytoplankton isolated from the Lower Great Lakes. J. Great Lakes Res. 34:1-11.

Janssen, C. R., and D. G. Heijerick. 2003. Algal toxicity tests for environmental risk assessments of metals. Rev. Environ. Contamin. Toxicol. 178:23-52.

Kola, H., and K. J. Wilkinson. 2005. Cadmium uptake by a green alga can be predicted by equilibrium modelling. Environ. Sci. Technol. 39:3040-3047.

Lead, J. R., K. J. Wilkinson, K. Starchev, S. Canonica, and J. Buffle. 2000. Determination of diffusion coefficients of humic substances by fluorescence correlation spectroscopy: role of solution conditions. Environ. Sci. Technol. 34:1365-1369.

Leenheer, J. A., D. M. McKnight, E. M. Thurmand, and P. MacCarthy. 1995. In Humic substances in the Suwannee River, Georgia: Interactions, properties and proposed structures; USGS Water Supply Paper 2373; U.S. Geological Survey: Denver, CO.

Lin, J.-H., W.-C. Kao, K.-P. Tsai, and C.-Y. Chen. 2005. A novel algal toxicity testing technique for assessing the toxicity of both metallic and organic toxicants. Water Res. 39:1869-1877.

Maldonado, M. T., R. F. Strzepek, S. Sander, and P. W. Boyd. 2005. Acquisition of iron bound to strong organic complexes, with different Fe binding groups and photochemical reactivities, by plankton communities in Fe-limited subantarctic waters. Global Biogeochem. Cyc. 19:GB4S23.

McKay, R. M. L., and others. 2005. Impact of phytoplankton on the biogeochemical cycling of iron in subantarctic waters southeast of New Zealand during Fe cycle. Global Biogeochem. Cycl. 19:GB4S24.

Morel, F. M. M., J. C. Westall, J. J. G. Rueter, and J. P. Chaplick. 1975. Description of algal growth media AQUIL and FRAQUIL. Technical Note, R. M. Parsons Laboratory for Water Resources and Hydrodynamics, Massachusetts Institute of Technology, Cambridge, MA.

Naito, K., M. Matsui, and I. Imai. 2005. Ability of marine eukaryotic red tide microalgae to utilize insoluble iron. Harmful Algae 4:1021-1032.

Porta, D., G. S. Bullerjahn, M. R. Twiss, S. W. Wilhelm, L. Poorvin, and R. M. L. McKay. 2005. Determination of bioavailable Fe in Lake Erie using a luminescent cyanobacterial bioreporter. J. Great Lake Res. 31:180-194.

- , K. Durham, A., S. W. Wilhelm, M. R. Twiss, and R. M. L. McKay. 2003. Physiological characterization of a Synechococcus sp. (Cyanophyceae) strain PCC 7942 irondependent bioreorter for freshwater environments. J. Phycol. 39:64-73. 
Price, N. M., and F. M. M. Morel. 1998. Biological cycling of iron in the oceans, p. 1-36. In A. Sigel and H. Sigel [eds.], Iron transport and storage in microorganisms, plants and animals: Metal ions in biological systems. Marcel Dekker.

Slaveykova, V. I., and K. J. Wilkinson. 2005. Predicting the bioavailability of metals and metal complexes: critical review of the biotic ligand model. Environ. Chem. 2:9-24.

Streb, C., P. Richter, T. Sakashita, and D. P. Haeder. 2002. The use of bioassay for studying toxicology in ecosystems. Curr. Topics Plant Biol. 3:131-142.

Sunda, W., and S. Huntsman. 2003. Effect of pH, light, and temperature on Fe-EDTA chelation and Fe hydrolysis in seawater. Mar. Chem. 84:35-47.

Tan, T. L. 1986. Construction and use of a dialysis chamber for investigating in situ toxicity of heavy metals on bacteria. ERBAM - Deuxième Colloque International de Bactériologie marine - CNRS, IFREMER, Actes de Colloques 3:589-595.

Twiss, M. R., J. C. Auclair, J.-C. Rueter, and M. N. Charlton. 2000. An investigation into iron-stimulated bphytoplankton productivity in epipelagic Lake Erie during thermal stratification using trace metal clean techniques. Can. J. Fish. Aquat. Sci. 57:86-95.

, L.Granier, P. Lafrance, and P. G. C. Campbell. 1999. Bioaccumulation of 2,2_,5,5_-tetrachlorobiphenyl and pyrene by picoplankton (Synechococcus leopoliensis Cyanophyceae): Influence of variable humic acid concentrations and pH. Environ. Toxicol. Chem.18:2063-2069.

and P. G. C. Campbell. 1998. Trace metal cycling in the surface waters of Lake Erie: linking ecological and geochemical fates. J. Great Lakes Res. 24:791-807.

, P. G. C. Campbell, and J.-C. Auclair. 1996. Regeneration, recycling, and trophic transfer of trace metals by microbial food-web organisms in the pelagic surface waters of Lake Erie. Limnol. Oceanogr. 41:1425-1437.

Van Leeuwen, H. P. 1999. Metal speciation dynamics and bioavailability: inert and labile complexes. Environ. Sci. Technol. 33:3743-3748.

Welschmeyer, N. A. 1994. Fluorometric analysis of chlorophyll $a$ in the presence of chlorophyll b and pheopigments. Limnol. Oceanogr. 39:1985-1992.

Whitfield, M., and D. R. Turner. 1979. Critical assessment of the relationship between biological thermodynamic and electrochemical availability, p. 657-680. In E.A. Henne [ed.], Chemical modeling in aqueous systems. ACS Symposium Series, American Chemical Society, Washington, DC 93.

Wilkinson, K. J., and J. Buffle. 2004. Critical evaluation of physicochemical parameters and processes for modelling the biological uptake of trace metals in environmental (aquatic) systems. IUPAC Ser. Anal. Phys. Chem. Environ. Sys. 9:445-533.

Yoshida, M., K. Kuma, S. Iwade, Y. Isoda, H. Takata, and M. Yamada. 2006. Effect of aging on the availability of freshly precipitated ferric hydroxide to coastal marine diatoms. Mar. Biol. 149:379-392.

Yoshida, T., K.-i. Hayashi, and H. Ohmoto. 2002. Dissolution of iron hydroxides by marine bacterial siderophore. Chem. Geol. 184:1-9.

Submitted 2 March 2007

Revised 7 December 2007

Accepted 20 February 2008 